\title{
Herencia y transmisión patrimonial en la Corona de Castilla al inicio de la Época Moderna
}

Inheritance and patrimonial transmission in Castile at the beginning of Early Modern Times

Ofelia Rey Castelao

Universidad de Santiago de Compostela, España

ofelia.rey@usc.es

\section{ReSUMEN:}

Este artículo analiza varios aspectos fundamentales de la herencia y la transmisión del patrimonio familiar desde el reinado de los Reyes Católicos hasta el final del Concilio de Trento (1563). Se aborda la renovación de las leyes civiles (Leyes de Toro, 1505) y de las normas eclesiásticas (sínodos diocesanos); el reflejo de ambas en las familias campesinas; la diversidad territorial de los sistemas de herencia y transmisión patrimonial en áreas rurales de Castilla, y el renovado marco judicial en el que se resolvieron los conflictos por esos temas.

Palabras clave: Leyes de herencia, Transmisión, Patrimonio, Castilla, Inicios Edad Moderna.

\begin{abstract}
:
This article analyzes several fundamental aspects of the inheritance and the transmission of the family patrimony since the reign of the Reyes Católicos at the end of the Council of Trent (1563): the renewal of civil laws (Leyes de Toro, 1505) and ecclesiastical norms (diocesan synods); the effect of these laws and synods in peasant families; the territorial diversity of the inheritance and patrimonial transmission systems in rural areas of Castilla; the renewed judicial framework he renewed judicial framework to resolve conflicts over these issues.
\end{abstract}

KEYWORDS: Laws of inheritance, Transmission, Patrimony, Castilla, Early Modern Age.

\section{INTRODUCCIÓN}

Existe desde hace años una abundante bibliografía sobre historia social de la familia en la que la herencia y la transmisión patrimonial se estudiaron de forma paralela -a partir de la historia del derecho- o a posteriori, a raíz del interés de la historia de las mujeres en ambas cuestiones (García González, 2008 y 2009; García González y Crespo Sánchez, 2017). Esto es más evidente en lo que respecta al período elegido, que va desde los Reyes Católicos hasta el final del Concilio de Trento en 1563, una etapa esencial por cuanto en la Corona de Castilla se modernizaron y fijaron el marco legal de la familia y el cuadro institucional en el que esta tendría que resolver sus conflictos. Nos interesa de forma específica el ámbito rural, el menos atendido por la bibliografía reciente a pesar de albergar a la inmensa mayoría de la población castellana, y plantear varias cuestiones clave, algunas todavía necesitadas de atención.

Empezando por ahí, conviene señalar que herencia y transmisión patrimonial, así como la comparación entre los diferentes sistemas, se han estudiado casi solamente en las leyes, sin tener en cuenta la estructura, la naturaleza y las relaciones de la familia y sin observar la aplicación de la ley o su transgresión, o la superposición legal -derecho real, normas de la Iglesia, costumbres locales- y la diversidad jurisdiccional. No se ha subrayado lo bastante que, en este período, las leyes se imprimieron y que su conocimiento se hizo más amplio y sencillo entre los profesionales del derecho y las autoridades civiles y eclesiásticas; que se incrementó el número de notarios y escribanos, esenciales no sólo para llevar al papel todo tipo de acciones privadas, sino también para que estas se adecuaran a las leyes de la monarquía; y que el sistema judicial de la Corona se expandió y se 
reforzó, con lo que contribuyó a la regularización de lo privado y de lo colectivo por la vía de las sentencias. Y se ha pasado por alto el efecto de las migraciones internas y ultramarinas -novedad con respecto a la Edad Media-, lo que pone sobre la mesa, entre otros aspectos, las capacidades de las esposas de ausentes. Obviamente, sería esencial conocer bien los caracteres de las familias, su distribución territorial y la relación entre zonas agrícolas y regímenes demográficos para entender todo lo referente a la transmisión patrimonial y para comprobar si en el siglo XVI estaba ya asentado lo que con facilidad se ha podido constatar para el siglo XVIII.

Carencias y sesgos se deben en gran medida a falta de fuentes fundamentales para hacerlo: no hay censos nominativos porque los poderes civiles no los implementaron y hay pocos registros parroquiales porque los párrocos rurales, en especial en zonas de hábitat disperso, no cumplieron las órdenes recibidas de los obispos desde 1480 para que los llevasen. Fuera de la legislación de la monarquía y de los sínodos episcopales, la mayor riqueza está en las escrituras notariales, esenciales para estudiar el régimen del matrimonio -dotes, contratos nupciales-, las disposiciones personales sobre la herencia -testamentos, codicilos, particiones- o de cesiones de patrimonio -donaciones, mayorazgos-, así como en las discordias o acuerdos entre partes - poderes para pleitos, concordias, convenios-. Para observar las desavenencias por herencias y repartos la clave está en los procesos judiciales civiles; los eclesiásticos lo son para los derivados del matrimonio o de la filiación y los inquisitoriales, para la bigamia. Es de reconocer el interés de otra documentación eclesiástica, como las dispensas de consanguinidad o las constituciones de capellanías para establecer hijos en el clero. Las cartas de emigrantes a las Indias y otros textos privados completan un largo e irregular elenco.

\section{EL MARCO LEGAL EN EL ESPACIO CASTELLANO}

Producto de la modernización de la monarquía, las leyes de Toro de 1505 regularon todo lo relacionado con la familia y la herencia en la Corona de Castilla. Se trataba de unificar la diversidad territorial y el viejo derecho con el común en un código único (Gacto Fernández, 1987a). No obstante, se mantuvieron usos particulares, muy importantes en el campo, por estar más adaptados a la realidad, si bien se interpuso la acción de la justicia para evitar que esos usos ocupasen el espacio situado entre la ley y la práctica o colisionasen con las normas. Para la implantación y aplicación de esas leyes fue esencial la nueva planta judicial de la monarquía, que se impuso sobre el denso mapa señorial castellano e interfirió en la vida privada por la vía de sus resoluciones.

En general, las leyes de Toro reafirmaron la autoridad del padre de familia, la igualdad entre hijos e hijas para recibir la herencia, el control legal del marido sobre el patrimonio de la esposa y la limitada capacidad de acción de las mujeres (Ruiz-Gálvez, 1982). Desde 1505 la Corona apenas hizo cambios legales, pero es preciso tener en cuenta los numerosos sínodos que se realizaron en todas las diócesis desde fines del siglo XV hasta el Concilio de Trento (García García, 1984), ya que todos adoptan medidas sobre el matrimonio, las disposiciones testamentarias, la filiación y el parentesco espiritual (Rey Castelao, 2009). No en vano, la monarquía se había ido haciendo con el control de los obispos y estos eran sus colaboradores necesarios; más todavía, si cabe, en el ámbito rural, donde la presencia del poder real estaba más diluida (Catalán Martínez, 2004).

El matrimonio era el epicentro de los dos ámbitos legales y en el campo lo era también de la costumbre, como se constata en las ordenanzas de muchos pueblos. En la normativa civil, el permiso para casarse dependía del padre o de la madre viuda, que podían excluir de la herencia a los hijos e hijas que lo hicieran sin su licencia o sin la edad legal. Esto no excluía la voluntad y libertad de los contrayentes, que era esencial en la normativa eclesiástica. La monarquía vigilaba el matrimonio de forma diferente de la del clero, cediendo a este el control ante situaciones como las bodas clandestinas o las celebradas mediante coacción. A comienzos de la Edad Moderna esta era una preocupación importante, derivada de cierta imprecisión canónica sobre el matrimonio y la importancia de la dote. Por esto, la legislación real desplegó diversos resortes preventivos y coactivos, e incluso mantuvo leyes viejas, como las que prohibían obligar a las mujeres a casarse o que un señor forzase a un 
vasallo a contraer matrimonio, o las que condenaban a los vasallos a que se casasen con una hija o pariente de su señor sin permiso de este. Los obispos, por su parte, insistieron a los párrocos para que registrasen las bodas, lo que respondía a la necesidad de regularizar el matrimonio, reducir el amancebamiento, asegurar la edad y la libertad de los novios, y prevenir la clandestinidad y la bigamia, problemas que los sínodos mencionan como frecuentes y preocupantes y que son la parte visible de prácticas que organizaban la transmisión del patrimonio familiar mediante las bodas.

En efecto, en Castilla la boda era un momento clave, tanto por la entrega de la dote de la novia como porque la pareja se regiría desde entonces por el régimen de bienes gananciales. Ambos, dote y bienes, quedaban bajo administración del marido, aunque con matices, ya que si bien las mujeres casadas necesitaban licencia marital para todas las acciones legales, había diversos mecanismos para eludirla (Collantes de Terán, 1997). La dote era una obligación paterna basada en que las mujeres cooperasen en la creación del hogar, pero también era un patrimonio propio de ellas y su defensa en caso de enviudar y ante condiciones adversas (García Fernández, 1999); el marido debía restituirlo si la unión se disolvía, y si él malgastaba los bienes, ella podía reclamarlos judicialmente con preferencia a cualquier acreedor (Pérez Álvarez, 2003). Si la esposa moría antes y la pareja no tenía hijos, la dote retornaba a los padres de la esposa, lo que seguramente era poco frecuente. Por todo esto, debería reconocerse que el sistema castellano protegía a las mujeres y las situaba en un nivel relevante en el contexto familiar: es menos evidente si las beneficiaba más o menos el sistema hereditario en el que se enmarcaba la dote, es decir, el igualitario, dominante en casi toda Castilla, que el desigual, empleado en amplias zonas norteñas.

Las dotes eran un importante adelanto de la herencia en los territorios rurales de familia nuclear y régimen hereditario igualitario (Barbazza, 2000; Núñez Roldán, 2009; García Barriga, 2009), y todavía más en los de dominio de la familia troncal y herencia a un único hijo o en régimen de mejora amplia, la de tercio y quinto, en el cual la dote de la esposa del heredero servía para pagar las dotes y herencias de los hermanos y hermanas de este. Ahora bien, no conviene generalizar, por cuanto en los sectores económicos débiles del ámbito rural era muy frecuente el trabajo prenupcial, de modo que los ingresos obtenidos por los miembros de la pareja solían ayudarlos a establecerse. Por ley, los padres mantenían el título y el usufructo de los recursos y de los bienes adquiridos por los hijos con su trabajo o por vía de donación, y si se emancipaban, podían darles los bienes ganados o reservarse la mitad del usufructo, un aspecto que sí es relevante en el siglo XVI dada la frecuencia del servicio doméstico o de otros trabajos asalariados prenupciales, que con frecuencia implicaban migraciones temporeras o desplazamientos a las ciudades, de modo que no todo dependía de las aportaciones de los padres (Vassberg, 1996; Rey Castelao, 2016a).

En cuanto a la sucesión, la ley establecía la legítima obligatoria y la igualdad entre herederos forzosos hombres y mujeres- de, al menos, cuatro quintos de la herencia. Sin embargo, las diferencias territoriales eran importantes por cuanto la ley daba un amplio margen de libertad, de modo que era posible mejorar a un hijo o una hija en un tercio de cuatro quintos, quedando el otro quinto para libre disposición, que los padres podían acumular al tercio de mejora. La herencia total se partía después de pagar gastos, obligaciones, créditos, legados, donaciones y el quinto libre, lo que podía disminuir la legítima hasta hacerla inviable como base para crear una familia allí donde la economía agraria dependía de las explotaciones familiares y no del salario. Las leyes de Toro regularon y limitaron el mayorazgo -vínculo de bienes indisolubles e inalienablesy su designación con preferencia al hijo primogénito, pero era una práctica de los grupos más poderosos.

Por costumbre, adaptación y conveniencia, los territorios no forales del Norte optaron por el sistema de mejora, variable en su alcance -corta, de tercio o de quinto, o larga, de tercio y quinto- y en la elección del hijo o hija mejorados, mientras que en la mayor parte de Castilla dominó la partición igualitaria. Ahora bien, en ambas fórmulas se solía favorecer o compensar a algún hijo o hija mediante avances de la herencia a través de dotes y donaciones intervivos, o de correctivos como los legados testamentarios, constatables en las escrituras notariales, e incluso fórmulas opacas como las ventas y préstamos falsos, para eludir las leyes. Habría que añadir regalos o cesiones no escriturados, que sólo se descubren en los pleitos. 
Debe tenerse en cuenta que los hijos podían recibir herencias totales o parciales - parcelas, reses, dinero, etc.- de parientes sin descendencia: eran los herederos o herederas de socorro de parejas o personas sin hijos, lo que no sólo dependía de la biología -esterilidad, mortalidad, soltería definitiva-, sino también del modelo de familia, más o menos amplia, cercana y ensamblada. La elevada proporción de quienes hacían testamento estando en esas circunstancias es un indicio de esas prácticas; de ahí el interés de su cálculo. Esos reajustes también dependían de la sociabilidad rural, ya que los donantes podían ser padrinos o madrinas no necesariamente emparentados con sus herederos; por ello, la importancia que las investigaciones recientes dan a las prácticas del padrinazgo bautismal (Rey Castelao, 2015).

Por testamento, los cónyuges podían designarse mutuamente como herederos y hacerse donaciones, limitadas por la legítima de los hijos. Si no testaban, el superviviente sólo podía heredar si no había parentela colateral. Debe recordarse que las mujeres podían testar de lo suyo sin licencia marital, lo que les daba una relativa libertad, y esto explica la abundancia de testamentos femeninos. Las viudas accedían a la plena capacidad legal pero ello no les daba una ventaja especial porque en su mayoría quedaban en una situación económica débil, aun cuando tenían desde el siglo XV la posibilidad de volver a casarse antes de un año sin perder los bienes del primer marido. Cuando había menores, serían sometidos a la tutela de un tutor fijado por testamento; de no haberlo, era la madre quien la asumía - podía perderla si se casaba de nuevo-, y debía rendir cuentas de su administración, pero tampoco ha de sobredimensionarse este aspecto pues solían ser nombradas como tutoras por sus maridos, e incluso como albaceas.

\section{LA REALIDAD FAMILIAR RURAL Y SU CONTEXTO}

La legislación de este período no contenía grandes novedades con respecto a la medieval -su clave estaba en la unificación, la modernización y la publicación-, y probablemente no provocó cambios sustanciales en el sistema de herencia. Ahora bien, seguramente se produjo un mayor ajuste de las costumbres con las leyes por la intermediación de los escribanos y notarios -regularizados por entonces (Extremera Extremera, 2009)-, que escrituraban las disposiciones nupciales o testamentarias, y de los jueces, que resolvían los conflictos ulteriores, como veremos. Lo más que se puede afirmar es que las familias hicieron un uso diverso de los recursos jurídicos e institucionales a su alcance, adaptándolos a su conveniencia, para trasvasar sus patrimonios a la siguiente generación.

Podemos dar por hecho el impacto del contexto demográfico y económico en el que la legislación se aplicó: en nuestro período, se vivió en Castilla un notable crecimiento de la población rural y de la producción agraria, y, por lo tanto, la relación entre recursos y población no estuvo sometida a excesivas tensiones. Por otra parte, la movilidad intrapeninsular, bastante intensa, en especial del campo a las villas y ciudades, y la emigración a Indias advierten de la apertura de oportunidades que permitieron a muchos hijos e hijas depender menos de una posible herencia, y también de la desarticulación de familias por ausencia de algunos de sus componentes.

En el ámbito rural, los regímenes de propiedad y de usufructo, e incluso el señorial y el de uso de los bienes colectivos, y las costumbres eran relevantes, al determinar en muchos casos el acceso a los medios de producción (Casey, 2011). Allí donde la unidad familiar estaba en simbiosis con una explotación agraria de propiedad plena o de usufructo a largo plazo y sin gran riesgo de evicción, en general predominó la partición desigual; no en vano eran también los territorios de explotaciones de tamaño pequeño que era preferible no partir en cada generación. Ese era el caso de gran parte del Norte, de Galicia en especial, donde, en este período, las grandes instituciones rentistas estaban cediendo sus tierras mediante foro a cabezas de familia, por su vida y otras dos. Donde lo hacían la gran propiedad y el trabajo rural asalariado o fórmulas mixtas arriendos a corto y medio plazo-, era mayoritaria la herencia igualitaria. En ambos casos el matrimonio era clave, por lo dicho, y porque también lo era para acceder a los bienes comunales, ya que era casi general la 
reserva a favor de los casados de ciertos derechos y espacios colectivos, como se recoge por escrito en este período en numerosas ordenanzas concejiles (Rubio Pérez, 2012).

El matrimonio era condición para la emancipación y el gozne para prever la sucesión, de forma que el modelo matrimonial era inseparable de las prácticas hereditarias. Pero es difícil hablar de estrategias cuando la mayoría de las familias campesinas tenía pocos bienes para repartir y vivía en un equilibrio económico precario e inestable. Eran los grupos rurales más acomodados, como los campesinos fuertes leoneses y castellanos o los hidalgos rurales del Norte, los que tenían medios y poderes para diseñar estrategias acumulativas (Ferrer i Alós, 2011).

Lamentablemente, no es fácil definir los modelos familiares rurales y ponerlos en relación con los dos grandes sistemas de herencia y captar sus cambios. Los únicos datos ilustrativos son los de fines del siglo XVI; es decir, anteriores a la crisis finisecular y del cambio de tendencia. Sabemos que en Castilla la Vieja y Andalucía el tamaño familiar estaba en torno a 4,5 componentes y que era menor en la mayor parte de Galicia; en general, predominaba la familia nuclear. La familia troncal era importante en el Norte pero distaba de ser general, ya que la nuclear dominaba en áreas de costa cantábrica y en toda Galicia, salvo el interior limítrofe con Asturias y León.

La edad de las mujeres al casarse, clave en la formación de la familia, está poco documentada: en Castilla la Nueva era en torno a 22 años y de 20 en Castilla la Vieja. La edad precoz se da en territorios de herencia igualitaria, donde no se podía esperar mucho de la herencia; en esas zonas también era elevada la endogamia, acompañada de consanguinidad -en amplias zonas castellanas, entre el diez y el treinta por ciento (Chacón Jiménez y Hernández Franco, 1992)- lo que era tanto el resultado del hábitat concentrado en pueblos donde todos los vecinos eran parientes entre sí, como el de la voluntad o necesidad de concentrar recursos y fragmentos de patrimonios familiares. No hay datos sobre matrimonios a trueque, solución a las limitaciones legales y biológicas de la consanguinidad, cuya detección solo es posible por medio de las actas parroquiales.

En los territorios del Norte de heredero preferencial o mayoritario, las previsiones destinadas a evitar el fraccionamiento del patrimonio implicaban prácticas para formar parejas con similares riqueza y estatus, $\mathrm{y}$ esto derivaba con frecuencia en exogamia geográfica. Como vía de control, las bodas se decidían en función de la localización de los bienes y del nivel económico de las familias, lo que daba a las mujeres un alto valor de cambio; esto no se contradice con el hecho de que el mismo régimen generaba un abundante celibato definitivo, ya que en áreas de alta presión demográfica este era también un modo de controlar la sucesión (Dubert, 1993; Sobrado Correa, 2001).

Para disponer la herencia, todo dependía del número de hijos, que podía orientar el comportamiento de las familias hasta llegar a los límites de lo legal. No era lo mismo distribuir el patrimonio en el Norte que en el Sur, pero las cifras son escasas y tardías, y habría que tener en cuenta la tasa de supervivencia diferenciada por sexos, en general más favorable a las mujeres, y el porcentaje de quienes, por falta de hijos, revirtieron sus herencias en la parentela. La sucesión incluía a los hijos naturales o de uniones no eclesiásticas -categoría más alta que los ilegítimos reconocida por la ley-, si no había hijos legítimos. Se suele admitir que la proporción de ilegítimos era alta en el XVI, de lo que apenas hay pruebas por falta de registros; en Castilla la Nueva era baja, pero era alta la de concepciones pre-nupciales (Barbazza, 2000), lo que, al darse en pueblos con alta consanguinidad, podría haber sido una forma de presionar a la autoridad eclesiástica para obtener la necesaria dispensa o que, ya concedida, esta se interpretase como un consentimiento para mantener una relación física, sin excluir tácticas de los novios para forzar la voluntad paterna.

Separaciones y divorcios eran raros, aunque sean llamativos en los tribunales eclesiásticos. Eran muy frecuentes las segundas nupcias masculinas -17,5\% en Extremadura, 28,5\% en pueblos de Castilla la Nueva-, lo que ampliaba el mercado matrimonial para las mujeres; además, si las segundas esposas no tenían hijos podían dejar sus bienes a los hijastros. Pero también implicaban una reorganización de la herencia que solía ser fuente de conflictos. Dado que las viudas pocas veces volvían a casarse, el porcentaje de hogares bajo su dirección era muy alto, menos en Castilla la Nueva (9\%-14\%), que en Galicia (17\%-20\%) o Castilla la Vieja 
(16\%-23\%) (Molinié-Bertrand, 1991; Barbazza, 1999). Este factor es relevante por la capacidad legal que ellas tenían en la gestión de la familia y de sus recursos.

En cuanto a los huérfanos, fueron una preocupación en aumento en este período. Los testamentos de los casados solían señalar un tutor (36-38\% en Extremadura), casi siempre a favor de las esposas (77\%), o se hacían disposiciones especiales, con frecuencia en atención a las hijas (Cava López, 2000). Esto último tenía un matiz moral, más claro en el hecho de que las huérfanas de clases humildes también pudieron beneficiarse de dotes fundadas por clérigos o notables, vistosa práctica de caridad todavía incipiente antes de Trento.

En definitiva, las familias revelan su capacidad adaptativa a lo permitido por las leyes y a las circunstancias demográficas y económicas, lo que explica la diversidad territorial, incluso en espacios decantados hacia un modelo, en lo que también se nota la influencia urbana. Dominante en Castilla, la herencia igualitaria reducía la importancia del linaje y reforzaba la familia conyugal y la igualdad entre sexos, pero en buena medida esto era teórico (García Fernández, 2002). Así, por ejemplo, en Castilla la Nueva se ha comprobado la frecuencia de las dotes $-43 \%$ de las bodas- a cuenta de la herencia; que los hijos trabajaban antes de casarse pero muchas hijas tenían que esperar a la muerte de los padres para hacerlo; que en sus testamentos, los esposos se daban mutuamente el usufructo de la casa y parte de la tierra -los gananciales- y que más del setenta por ciento nombraban albaceas a sus cónyuges, o que al morir el padre, se reunían todos los bienes para el teórico reparto igualitario, lo que incluía las dotes de las hijas, y las donaciones a estas o a hijos; pero también eran frecuentes las mejoras y legados, y muchas compraventas de bienes eran ficticias, pues escondían formaciones de patrimonio para la constitución de familias nuevas (Barbazza, 2000). Por otra parte, los hijos se emancipaban al casarse pero vivían cerca de sus padres y las otras ramas de la familia, lo que mitigaba los efectos de la precariedad.

En la mayor parte de Galicia y en parte de Asturias se optó por la mejora a favor de un hijo o una hija, a diferencia de algunas zonas cántabras, asturianas y del interior gallego, donde se daba la mejora larga a un hijo, el primogénito por lo general. Un caso diferente es el de la población hidalga, mayoritaria en Cantabria y Asturias y abundante en la Galicia interior limítrofe con esta última, compuesta por familias campesinas en las que se advierte su marcado concepto de casa. Una minoría rica estaba marcada, a su vez, por el de linaje, parentela artificial o de patronazgo, cuya cabeza asumía la dirección y la protección de sus componentes, y que empleaba el mayorazgo buscando un estatuto social preeminente. Esto implicaba un fuerte coste social, al exigir un estricto control del acceso al matrimonio a través de la endogamia y la consanguinidad entre linajes preferenciales y miembros de un mismo árbol; y un fuerte coste económico para pagar esas estrategias, así como las legítimas y dotes de los no herederos y la colocación de estos en el clero u otros destinos. Lo único positivo es el alto valor de cambio que tenían las mujeres (Solórzano Telechea, 2002).

\section{DISENSIONES Y PROBLEMAS EN LOS SISTEMAS DE TRANSMISIÓN}

Una dimensión fundamental y menos estudiada de lo que merece es la gestión de la disconformidad con cualquier aspecto de la transmisión y de la herencia. Conviene tener en cuenta que no sólo estaba prevista por la ley, sino que también podía llevarse ante la justicia con relativa facilidad. Entre la Corona y los vasallos se interponían las justicias locales y las jurisdicciones señoriales que ejercían en primera instancia y, en no pocos casos, también en apelación, y ante cuyos jueces -los más próximos a las familias, en realidad- se presentaba un sinfín de conflictos. La novedad de este período radica en la reforma y modernización judiciales por los Reyes Católicos y Carlos I: a la real Chancillería de Valladolid se añadieron en 1494 la Chancillería de Ciudad Real, trasladada en 1505 a Granada, y las reales audiencias de Galicia (1480), Sevilla (1493-1526) y Canarias (1526). La mejor formación y profesionalidad de sus jueces y la disponibilidad mayor de instrumentos de consulta, impresos y asequibles, fueron claves para superponerse a la diversidad jurisdiccional y a la dudosa cualificación de los jueces inferiores, y para unificar criterios mediante las sentencias que dictaban y creaban precedentes. 
Es necesario plantear si el campesinado, analfabeto y pobre en su inmensa mayoría, tenía información sobre sus opciones legales en caso de conflicto y, en concreto, sobre las que le permitieran resolverlo sin mucho coste y con posibilidades de éxito. Para esto, las ordenanzas propias de los tribunales de la Corona recogían las peculiaridades de cada territorio y resolvían problemas como la distancia, el hábitat o las diferencias lingüísticas; disponían, además, de mecanismos para facilitar la defensa de los más débiles, incluso de las mujeres de ausentes. Esto facilitó la proliferación de pleitos, parte visible de una intensa conflictividad en temas de herencia y transmisión, difícilmente medible: sería preciso ver todo tipo de juzgados y los protocolos de escribanos y notarios que registraron tanto los poderes para pleitos, como las concordias o convenio que evitaban llegar a los tribunales y, con ello, mayores costes y tensiones en la familia y en la comunidad.

La consulta de esas ordenanzas permite conocer los procedimientos que permitían a los vasallos apelar las resoluciones de las justicias locales, o eludirlas, ya que gracias a varios de esos procedimientos las dos chancillerías y las audiencias podían actuar en primera instancia. Los más importantes eran los "casos de corte", a los que podían acogerse las personas de determinada calidad -incluye a pobres- "quitando su conocimiento al juez inferior"; las "provisiones ordinarias", que "se despachan como se piden" -facilitaban la tramitación-; el "derecho de graciosa", que permitía a los deudores recuperar sus bienes en caso de embargo y venta judicial; y la "provisión ordinaria de viudas", mediante la cual los jueces les dejaban resistirse a pagar deudas o solicitar la inhibición de la justicia local, entre otras opciones. Varias de esas fórmulas facilitaban el acceso de las mujeres a la justicia, lo que incluía a las casadas, ya que los jueces podían habilitarlas para actuar sin permiso marital si la causa lo requería o si los maridos estaban ausentes (Muñoz García, 1991). La existencia de abogados y procuradores de pobres también tenía importancia, en especial para huérfanos y mujeres en mala situación económica o carentes de vínculos familiares.

En cuanto al empleo de esas opciones, no es posible calcularlo por la deficiente conservación de los procesos pero es un indicio que todos los tribunales de la Corona tuvieran que ampliar el número de sus jueces para atender la avalancha de conflictos que llegaron a sus mesas. Así sucedió en la Audiencia de Galicia, instancia superior de ese reino -sólo apelable a la Chancillería de Valladolid-, creada en 1480 para atender un territorio de señorío eclesiástico y nobiliario, con más de un noventa por ciento de población rural y un hábitat disperso. Ese tribunal dispuso de los procedimientos mencionados ante una intensa conflictividad familiar por herencias, dotes y tutelas de menores: los vasallos acudieron a la Audiencia para eludir a los jueces señoriales y solicitar un auto ordinario en primera instancia o para apelar las sentencias de estos, en general poco formados y demasiado cercanos a los problemas que juzgaban (Rey Castelao, 2016b).

En todas partes, la conflictividad familiar rural tenía la misma tipología (Casey, 1996), sobresaliendo los pleitos referidos a las dotes (Nausia Pimoulier, 2008), incoados por viudas e incluso por casadas habilitadas por los jueces. El litigio más común derivaba del malgasto o malversación de la dote, lo que solía encubrir problemas en las economías familiares, ya que, al permitirlo la ley, el marido había utilizado los bienes dotales para endeudarse; a veces se intuye el consentimiento de ellas, pero en otras no solo su falta sino también el uso de la violencia (Mantecón Movellán, 2002).

Parte de los conflictos era competencia de los tribunales eclesiásticos, a cuyo ámbito tocaba lo referente al matrimonio, salvo la bigamia, responsabilidad de la Inquisición. Dado que la clave de la transmisión estaba en el matrimonio, monarquía e Iglesia trataron de mantenerlo bajo su control, de acuerdo entre sí por lo general, pero no sin tensiones (Irigoyen López, 2011). El problema más agudo antes de 1563 era el matrimonio clandestino, es decir, el contraído sin la solemnidad requerida; con frecuencia solía ser cosa de jóvenes sin el consentimiento o el conocimiento de sus padres o tutores, sin testigos o sin la presencia del párroco, si bien era la falta de solemnidad lo que los convertía en clandestinos (Sánchez-Arcilla, 2010). Se temían sus causas -consanguinidad, parentesco espiritual, bigamia- y sus consecuencias sobre la familia -problemas de herencia y de autoridad paterna- y sobre la comunidad -desorden social, mezcla racial-. Prohibido sin ambages por las leyes de Toro, se permitía a los padres desheredar a los hijos así casados, en tanto que novios y testigos podían ser condenados a perder sus bienes, al destierro e incluso a la horca (Aznar Gil, 2006). Aun así, los diputados 
de las Cortes de Castilla solicitaron a la Corona medidas más eficaces en 1537, 1538, 1539, 1548 y 1555 a 1558. Por su parte, los obispos lo condenaron con dureza en los sínodos anteriores al Concilio de Trento, estipulando severos castigos contra los novios - los hijos de estas uniones se considerarían ilegítimos-, contra los clérigos consentidores y contra los testigos, lo que podía llegar a la excomunión. Según estos indicios, tales enlaces eran frecuentes, pero es difícil comprobarlo; así, por ejemplo, en los tribunales eclesiásticos de Zamora constituían el diez por ciento de los pleitos (Lorenzo Pinar, 1995), de modo que quizá fuese un problema de los grupos acomodados, celosos de sus estrategias nupciales. La clandestinidad no siempre era la táctica de una pareja para eludir la potestad paterna, sino que también acudían a ella padres cómplices ante la falta de dispensas eclesiásticas por consanguinidad o afinidad en uniones que consideraban interesantes en sus estrategias.

La segunda preocupación de las autoridades era la bigamia (Gacto Fernández, 1987b). En lo civil, desarticulaba a dos familias y tenía consecuencias negativas sobre la gestión del patrimonio y de los gananciales de la primera pareja, de la herencia y de la tutela de los hijos. Sucedía lo mismo con las segundas esposas, que perderían esta condición, y sus hijos pasarían a ser ilegítimos; si eran ellas las causantes, los efectos eran menores, por su mayor limitación legal. En lo eclesiástico, la bigamia afectaba a la moral y tocaba al dogma; por eso competía a la Inquisición. Ahora bien, su prevención y detección correspondían a los obispos; de ahí que los sínodos, especialmente en los del Norte, ordenasen a los párrocos que comprobasen la libertad de los contrayentes o la disolución del matrimonio previo, algo casi imposible por falta de registros matrimoniales. El sínodo de Burgos de 1503 relacionaba la bigamia con la emigración y en cierto modo a esto respondían las leyes reales de 1513 y 1549 que obligaban a los casados a llevar a sus esposas a Indias para reducir las separaciones de hecho y el abandono de muchas mujeres. No es posible calcular la bigamia, salvo que era entre $4 \%$ y $6 \%$ de los procesos inquisitoriales en especial entre 1535 y 1563 , si bien una parte de ellos implicaron a bígamos intrapeninsulares y no solo ausentes en América (Béthencourt, 1998). Los casos serían mucho más numerosos, a los que se añadían los de convivencia, calificados como amancebamiento o adulterio, menos penalizados y menos detectables (Collantes de Terán, 2014).

A los obispos les importaba menos la falta de aprobación paterna que la falta de libre consentimiento de los contrayentes; de ahí la insistencia de los sínodos en que tuvieran la edad mínima de matrimonio: catorce años el novio y doce la novia, inferior a la legal (Usunáriz Garayoa, 2005). El obispo de Burgos denunciaba en 1503 que "andando por las Montañas hemos visto escándalos sobre haber desposado los niños menores de seys años”, si bien esto no puede comprobarse. Las bodas precoces responderían a la organización de estrategias de familias fuertes interesadas en trabar acuerdos nupciales, para lo que se adelantarían como un modo de preservar sus intereses.

Los antídotos de los obispos contra esos problemas y contra los conflictos derivados eran unánimes. Insistían en la publicidad de las bodas mediante las amonestaciones dominicales; en que la comunidad conociese los impedimentos canónicos y los denunciase; que la boda se hiciese de día y “a campana tañida”, y en la parroquia de la novia, no en ermitas, monasterios o casas privadas, hábitos comunes entre los poderosos; que sólo oficiase el párroco y lo registrase en un libro haciendo constar la presencia de los padres o tutores y de los testigos -entre cinco y diez, dependiendo del tamaño del pueblo-. Los testigos en bodas campesinas solían ser vecinos, sacristanes y mayordomos de las parroquias, y su elección era relevante, ya que podían ser llamados a declarar en caso de pleitos posteriores. Los sínodos también recogían la celebración de la velación, ceremonia en la que la pareja, antes de convivir, intercambiaba su consentimiento en presencia del párroco, lo que también era un modo de controlar a posteriori la validez del matrimonio (Aznar Gil, 1989).

Ahora bien, la aplicación de unas normas que afectaban el epicentro del sistema familiar y comunitario fue lenta y dificultosa, como lo demuestran la reiteración y endurecimiento de los mandatos. No en vano esa aplicación correspondía a los párrocos, cuya forma de vida -concubinato, hijos bastardos- anulaba su poder ejemplarizante; por otra parte, al depender aquellos de los poderosos locales, que con frecuencia eran los 
titulares del patronato de las iglesias, se hacían cómplices de las prácticas de sus patronos, siempre destinadas a llevar a cabo sus estrategias nupciales hasta bordear lo ilegal (Saavedra, 2016).

El éxito de esas estrategias incluía su exhibición pública. Así pues, una preocupación de la monarquía y de los obispos fue el excesivo gasto en dotes y fiestas de bodas, utilizadas para dar publicidad a un acuerdo nupcial y demostrar el poder social y económico de las familias, por lo que derivaron en endeudamiento y en violentas disputas con ocasión de las celebraciones. En el ámbito rural se añadían graves abusos de los poderosos, como la costumbre de la ruega o recaudación de dinero u objetos entre vecinos y vasallos, que realizaban los parientes y amigos de la pareja, recurriendo a veces la coacción o a la fuerza. Los obispos prohibieron que los curas la hiciesen o permitiesen en sus parroquias, al tiempo que la monarquía se hacía eco de esas coacciones y de los brotes violentos, muy graves con ocasión de matrimonios clandestinos (Rey Castelao, 2019). Varias reales cédulas $(26 / 1 / 1492,3 / 12 / 1536)$ concuerdan con los sínodos en relacionarlos con la violencia y los pleitos entre bandos, haciendo especial hincapié en el Norte. Allí, las familias hidalgas con verdadero poder eran pocas y, al emplear el sistema de herencia prioritaria y una endogamia intensa, un acuerdo entre dos linajes podía desequilibrar a uno sobre otro. Esto daba ocasión a una inusitada conflictividad, que transmigraba hasta los vasallos y los implicaba en actos lesivos para sus escuetos patrimonios (Solórzano Telechea, 2002).

\section{Conclusiones}

Hemos abordado de forma sucinta, a partir de bibliografía reciente, varios aspectos clave que afectaron la herencia y la transmisión del patrimonio familiar en ámbitos rurales de la Corona de Castilla. Se han excluido los territorios que disponían de fueros propios para insistir en que, bajo un mismo marco legal -el de la monarquía, fijado en las Leyes de Toro de 1505-, existían fórmulas hereditarias adaptadas a las circunstancias demográficas y socio-económicas de cada zona, dentro de dos grandes modelos -el igualitario y el desigual- que procedían de la Edad Media. Como fecha final hemos marcado 1563, toda vez que la normativa eclesiástica establecida en el Concilio de Trento influyó en la normativa civil en cuestiones como el matrimonio, además de inducir a la monarquía a delimitar mejor los límites de la justicia canónica. En el período que media entre 1480 y 1563 los dos poderes colaboraron a partir de una nueva relación de dependencia de los obispos con respecto a los reyes. La autoridad diocesana fue esencial para la vigilancia y el control de las relaciones familiares en los ámbitos rurales a través de la red parroquial; de hecho, la normativa contenida en los sínodos es la que mejor refleja y resuelve problemas como el matrimonio clandestino u otras irregularidades que derivaban de estrategias para organizar la transmisión hereditaria sin respetar la libertad de los hijos; además, esa autoridad era la responsable de dar las dispensas por parentesco y por afinidad espiritual, algo de gran importancia, dada la frecuencia de la consanguinidad en espacios rurales, mientras que los tribunales eclesiásticos eran los que atendían una buena parte de los conflictos familiares. A falta de un funcionariado que controlase la aplicación de las leyes, hubo otros mediadores fundamentales que pudieron hacerlo con facilidad, toda vez que esas leyes estaban impresas y se podía adquirirlas a módico precio. Por un lado, los escribanos y notarios que pusieron por escrito las disposiciones particulares sobre la herencia o las acciones de concordia o de inicio de un pleito. Por otro, los jueces de los tribunales reales, renovados y dotados de personal con formación universitaria y con la posibilidad de utilizar procedimientos que les permitían actuar incluso en primera instancia en un espacio, el castellano, en gran parte señorial. El campesinado conservaba sus costumbres en la medida en que la monarquía lo permitió y siempre que no contradijesen lo que la ley decía; precisamente por esto, quienes se consideraron lesionados en sus intereses por las disposiciones paternas sobre la herencia, o por los repartos de esta, acudieron cada vez más a los tribunales de la corona. La lenta normalización de la transmisión hereditaria, perceptible en esos conflictos, se debió a la persistencia de la costumbre y de aquellas prácticas que estaban arraigadas. La falta o la lejanía de núcleos urbanos que generasen modelos socio-culturales nuevos y el analfabetismo generalizado del campesinado colaboraron con la incapacidad material de la monarquía para imponerse en el ámbito privado 
y con la dificultad que para los obispos suponía la escasa formación del clero parroquial y la dependencia de este con respecto a los poderosos, de modo que la modernización solo se percibe después de 1563 . No son cuestiones cerradas, sino necesitadas de profundización, pero cuya resolución se encuentra con carencias documentales importantes para el período inicial de la Edad Moderna y con la conveniencia de introducir en la investigación perspectivas como la cultural, habitualmente ajenas en el estudio de los temas relacionados con la herencia y la transmisión del patrimonio.

\section{REFERENCIAS}

Aznar Gil, F.R. (2006). Penas y sanciones contra los matrimonios clandestinos en la Península Ibérica. de la Facultad de Teologia, 57, 1, 343-369.

Barbazza, M. C. (1999). Las viudas campesinas de Castilla la Nueva en los siglos XVI- XVII. En M.T. López Beltrán (Ed.),De la Edad Media a la Moderna: mujeres, educación y familia en el ámbito rural y urbano (pp. 133-164). Málaga: Universidad de Málaga.

Barbazza, M. C. (2000). La Société paysanne en Nouvelle-Castille: famille, mariage et transmission des biens à Pozuelo de Aravaca (1580-1640). Madrid: Casa de Velázquez.

Béthencourt, F. (1998). La inquisición en la época moderna. Madrid: Akal.

Casey, J. (1996). La conflictividad en el seno de la familia. Estudis, 22, 9-26.

Casey, J. (2011). Familia, organización sociocultural y relaciones de poder. En F. Chacón y J. Bestard (Coords.), Familias: historia de la sociedad española (pp. 485-514). Madrid: Cátedra.

Catalán Martínez, E. (2004). El derecho de patronato y el régimen beneficial de la iglesia española en la Edad Moderna. Hispania Sacra, 56-113, 135-168.

Cava López, G. (2000).Infancia y sociedad en la Alta Extremadura durante el Antiguo Régimen. Cáceres: J.C. Brocense.

Chacón Jiménez, F. y Hernández Franco, J. (Coords.) (1992). Poder, familia y consanguinidad en la España del Antiguo Régimen. Barcelona: Anthropos.

Collantes de Terán, M.J. (1997). El régimen económico del matrimonio en el derecho territorial castellano. Valencia: Tirant Lo Blanch.

Collantes de Terán, M.J. (2014). El amancebamiento. Una visión histórico-jurídica en la Castilla moderna. Madrid: Dykinson.

Dubert, I. (1993). Historia de la familia en Galicia (1540-1830). Sada: Edicións do Castro.

Extremera Extremera, M.A. (2009). El notariado en la España Moderna. Los escribanos públicos de Córdoba (siglos XVI$X I X)$. Madrid: Calambur.

Ferrer i Alòs, Ll. (2011). Acceso y distribución de los medios de producción. Herencia y reproducción social. En F. Chacón Jiménez y J. Bestard (Coords.), Familias: historia de la sociedad española (pp. 255-324). Madrid: Cátedra.

Gacto Fernández, E. (1987a). El grupo familiar de la Edad Moderna en los territorios del Mediterráneo hispánico: una visión jurídica. En P. Vilar (Ed.), La familia en la España mediterránea (pp. 36-64), Barcelona: Crítica.

Gacto Fernández, E. (1987b). El delito de bigamia y la Inquisición española. Anuario de Historia del Derecho Español, $57,465-492$.

García Barriga, F. (2009). Familia y sociedad en la Extremadura rural de los tiemposmodernos (siglos XVI-XIX). Cáceres: Universidad de Extremadura.

García Fernández, M. (1999). La dote matrimonial, implicaciones sociales, sistemas familiares y práctica sucesoria: Castilla y Europa en la Edad Media. En D.S. Reher(Coord.), Matrimonio y nupcialidad: perspectivas interdisciplinares (pp. 78-100) Logroño: Universidad de La Rioja.

García Fernández, M. (2002). Herederos y beneficiarios. Igualdad hereditaria o heredar lo mismo. En A. Irigoyen López y A.L. Pérez Ortiz (Eds.), Familia, transmisión y perpetuación (ss. XVI-XIX) (pp. 105-133). Murcia: Universidad de Murcia. 
García García, A. (1984). SynodiconHispanum. Madrid: BAC.

García González, F. (2008). La historia de la familia en la Peninsula Ibérica: balance regional y perspectivas. Cuenca: Universidad de Castilla-La Mancha.

García González, F. (2009). La Historia de la familia en el mundo rural. En F. Chacón y J. Hernández (Eds.), Espacios sociales, medios familiares. La familia en la historiografía española (pp. 107-136). Murcia: Universidad de Murcia.

García González, F. y Crespo Sánchez, F.J. (2017). Radiografía de un impulso compartido. La historia de la familia en España e Iberoamérica (2000-2015). En O. Rey Castelao y P. Cowen (Eds.), Familias en el Viejo y el Nuevo Mundo (pp. 44-78). La Plata: Universidad Nacional de La Plata.

Irigoyen López, A. (2011). Estado, Iglesia y familia. La complejidad de los cambios legislativos y socioculturales. En F. Chacón Jiménez y J. Bestard (Coords.), Familias: historia de la sociedad española (pp. 515-614). Madrid: Cátedra.

Lorenzo Pinar, L. (1995). El Tribunal Diocesano y los matrimonios "de presente" y clandestinos en Zamora durante el siglo XVI. Studia Zamorensia, 2, 49-61.

Mantecón Movellán, T. (2002). La violencia marital en la Corona de Castilla durante la Edad Moderna. En A. Irigoyen López y A.L. Pérez Ortiz (Eds.), Familia, transmisión y perpetuación (ss. XVI-XIX) (pp. 19-55). Murcia: Universidad de Murcia.

Molinié-Bertrand, A. (1991). Les veuves dans l'Espagne classique. En R. Carrasco (Ed.), Solidarités et sociabilités en Espagne (XVI-XXe siècles)( p. 267). París: Les Belles Lettres.

Muñoz García, M.J. (1991). Las limitaciones a la capacidad de obrar de la mujer casada (1505-1975). Cáceres: Servicio de Publicaciones UNEX.

Nausia Pimoulier, A. (2008). Suegros, nueras y viudas ante los tribunales: la restitución de dotes (siglos XVI-XVII). En J.M. Usunáriz Garayoa y R. García (Coords.), Padres e hijos en España y el mundo hispánico: siglos XVI y XVIII (pp. 245-266). Madrid: Visor.

Núñez Roldán, F. (2009). Compromiso matrimonial, dote y ajuar femenino en el Bajo Guadalquivir (1513-1556). Archivo Hispalense, 279,127-139.

Pérez Álvarez, M.P. (2003). Observaciones sobre el "privilegiumexigendi" a favor de la mujer para la restitución de la dote. Studia et documenta historiae et iuris, 69, 611-622.

Rey Castelao, O. (2009). Femmes et héritage en Espagne au XVIIe siècle: stabilité légale et changements réels. XVIIe siècle, 244, 451-476.

Rey Castelao, O. (2015). Parrains et marraines en Galice aux XVIe -XIXe siècles. En G. Alfani y otros (Dirs.), Le parrainage en Europe et en Amérique Pratiques de longue durée (XVIe -XXIe siècle) (pp. 69-98). Bruselas: Peter Lang.

Rey Castelao, O. (2016a). Población, ocupación del territorio y migraciones rurales en la bibliografía española reciente. En F. García González, G. Béaur y F. Boudjabaa (Coords.), La historia rural en España y Francia, siglos XVI-XIX (pp. 35-56). Zaragoza: Prensas Universitarias.

Rey Castelao, O. (2016b). Las mujeres gallegas ante los tribunales: la defensa de lo suyo. Historia et Ius, 9. Recuperado de http://www.historiaetius.eu/uploads/5/9/4/8/5948821/rey_castelao_9.pdf.

Rey Castelao, O. (2019). Normes et pratiques de la cérémonie du mariage dans le Nord de l'Espagne avant le Concile de Trente. Bulletin de correspondance hellénique moderne et contemporaine, 1. Recuperado de https://journals.o penedition.org/bchmc/292.

Rubio Pérez, L.M. (2012). Bienes concejiles y régimen comunal. Claves, modelos y referencias del mundo rural durante la Edad Moderna. En M.J. Pérez Álvarez y L.M. Rubio Pérez (Eds.), Campo y campesinos en la España Moderna (pp. 87-152). Madrid: FEHM.

Ruiz-Gálvez, E. (1982).Statut socio-juridique de la femme en Espagne au XVIe siècle: une étude sur le mariage chrétien. París: Didier.

Saavedra, P. (2016). El clero rural en la España moderna. En F. García González, G. Béaur y F. Boudjaaba (Eds.), La historia rural en España y Francia (siglos XVI-XIX) (pp. 339-383). Zaragoza: Prensas Universitarias. 
Sobrado Correa, H. (2001). Las tierras de Lugo en la Edad Moderna. Economia campesina, familia y herencia, 1550-1860. A Coruña: F. Barrié.

Sánchez-Arcilla Bernal, J. (2010). La formación del vínculo y los matrimonios clandestinos en la Baja Edad Media. Cuadernos de Historia del Derecho, 17, 7-47.

Solórzano Telechea, J.A. (2002). Santander en la Edad Media: patrimonio, parentesco y poder. Santander: Universidad de Cantabria.

Usunáriz Garayoa, J.M. (2005). El matrimonio como ejercicio de la libertad en la España del Siglo de Oro. En J.M. Usunáriz Garayoa e I. Arellano (Eds.), El matrimonio en Europa y el mundo hispánico: siglos XVI y XVII (pp. 197-210). Madrid: Visor.

Vassberg, D.E. (1996). The village and the outside world in Golden Age Castile: mobility and migration in everyday rural life. Cambridge: Cambridge UP. 